represent a subgroup of patients with a low risk of progression to overt nephropathy. In support of this, the incidence of overt diabetic nephropathy increases steeply 10 years after onset of insulin dependent diabetes mellitus and decreases after 30 years. ${ }^{1}$ In addition, the prevalence of diabetic nephropathy clearly falls after 40 years.

\section{PREDICTIVE FACTORS}

Were there some clinical signs or symptoms to distinguish those patients who developed overt nephropathy from those who did not? In the study by Viberti et al, patients who developed overt nephropathy had a slightly longer duration of diabetes than those who did not. Among our initially normoalbuminuric patients, those who developed microalbuminuria or macroalbuminuria had a shorter duration of diabetes than those who remained normoalbuminuric, suggesting that long duration decreases rather than increases the risk of developing nephropathy in these patients. In addition, patients who developed microalbuminuria or macroalbuminuria had higher glycated haemoglobin concentrations during follow up than those who did not progress, indicating that poor glycaemic control contributed to the development of diabetic nephropathy. The patients who progressed to nephropathy also required a greater daily insulin dose and had lower high density lipoprotein cholesterol concentrations than the patients who remained normoalbuminuric. An increased insulin requirement suggests reduced insulin sensitivity, and low high density lipoprotein cholesterol concentrations have been attributed to insulin resistance." In line with the insulin resistance hypothesis, microalbuminuric patients who progressed to nephropathy had a higher body mass index than those who did not. An association between daily requirement of insulin and incidence of nephropathy has been reported. ${ }^{1}$

\section{SUMMARY}

In conclusion, in patients with insulin dependent diabetes mellitus of long duration microalbuminuria is no longer an important predictor of progression to overt diabetic nephropathy. The data also suggest that signs and symptoms of insulin resistance are common in patients who progress to overt nephropathy. Since the predictive value of microalbuminuria is different in patients with insulin dependent diabetes mellitus of over 15 years' duration, such patients should be excluded from trials aiming at preventing progression from microalbuminuria to overt proteinuria.

We thank Anna-Maija Teppo, for measuring urinary albumin concentrations. This study was supported by grants from the Sigrid Juselius Foundation, the Perklen Foundation, and the Nordisk Insulin Foundation.

1 Andersen AR, Christiansen JS, Andersen JK, Kreiner S, Deckert T. Diabetic nephropathy in twpe I (insulin-dependent) diabetes: an epidemiological study. Diabetologia 1983:25:496-501.

2 Borch-Johnsen K, Andersen PK, Deckert T. The effect of proteinuria on relative mortality in type 1 (insulin-dependent) diabetes mellitus. Diabut clogia 1985:28:590-6.

3 Viberti GC, Hill RD, Jarrett RJ, Argyropoulos A, Mahmud U, Keen $H$ Microalbuminuria as a predictor of clinical nephropathy in insulin-dependen dicroalbuminuna as a predictor of clinica

4 Mogensen CE, Christensen CK. Predicting diabetic nephropathy in insulindependent patients. N Engl F Med 1984;311:89-93.

5 Teppo AM. Immunoturbidimetry of albumin and immunoglobulin $G$ in urine. Clim Chem 1982:28:1359-61

6 Reaven G.M. Role of insulin resistance in human disease. Diabetes 1988;37 $1595-607$.

(Accepted 3 Seplember 1992)
Departments of Public Health, University of Helsinki, Mannerheimintie 96A, SF-00250 Helsinki Arja H Rimpelä, associate professor

Department of Public Health, University of Turku, Lemminkäisenkatu 1, SF-20520 Turku Matti K Rimpelä, acting associate professor

Department of Public Health, University of Tampere, PO Box 607, SF33101 Tampere

Elise A-L Kosunen, clinical lecturer

Correspondence to: $\operatorname{Dr} \mathrm{AH}$ Rimpelä, Department of Public Health, University of Oulu, Aapistiez SF-90220

Oulu, Finland.

\title{
Use of oral contraceptives by adolescents and its consequences in Finland 1981-91
}

\author{
Arja H Rimpelä, Matti K Rimpelä, Elise A-L Kosunen
}

\begin{abstract}
Objectives-To study use of oral contraceptives among Finnish teenagers during 1981-91 and how abortions, childbirths, sexually transmitted diseases, and cardiovascular diseases changed during this period.

Design-Biannual cross sectional surveys with mailed questionnaires from 1981 onwards and analysis of national statistics.

Setting-Finland.

Subjects-A nationwide sample of 14,16 , and 18 year olds. Sample size varied from 1249 to 3887 and response rate from $85 \%$ to $94 \%$.

Main outcome measures-Proportion taking oral contraceptive, fertility and abortion rates, hospital discharge rates, rates of sexually transmitted diseases.

Results-The proportion of teenagers taking oral contraceptives increased steadily. In 1991 the percentages among 14,16 , and 18 year olds were $2 \%$, $18 \%$, and $41 \%$ compared with $0 \cdot 2 \%, 7 \%$ and $22 \%$ in 1981. Most users had a steady partner $(80 \%$ of 16 year olds and $85 \%$ of 18 year olds). By 1989 rates of abortion had fallen from $12 / 1000$ to $9 \cdot 3 / 1000$ in 16 year olds and from $25 / 1000$ to $19 \cdot 2 / 1000$ in 18 year olds; fertility rates had fallen from $4 \cdot 5 / 1000$ to $2 \cdot 3 / 1000$ and from $23 \cdot 5 / 1000$ to $15 \cdot 3 / 1000$ respectively. Rates in 14 year olds fell only slightly. Gonorrhoea infection fell and HIV infection
\end{abstract}

remained rare. Rates of hospital discharge after thromboembolic venous disease rose slightly.

Conclusions-The increased use of oral contraceptives is the most likely explanation for decreasing abortion and fertility rates among teenagers. Increased reliance on the condom because of the threat of AIDS may increase unwanted pregnancies.

\section{Introduction}

The need for contraception among adolescents in developed countries is today undoubtable since sexual experience by late adolescence has become so common as to be normal.' However, fertility and abortion rates in teenagers suggest that the need for contraception is still not satisfied.

The first oral contraceptives introduced in the $1960 \mathrm{~s}$ were not suitable for adolescents because of their adverse effects on the growth and maturation of the menstrual cycle. The new low dose and microdose oral contraceptives overcame these problems and they were recommended for teenagers as well. ${ }^{3.5}$ As oral contraceptives offer a high degree of protection and are well tolerated among adolescents, ${ }^{5}$ increased use could be expected to reduce the rate of unwanted pregnancies.

Although oral contraceptives seem to reduce the risk of pelvic inflammatory disease, ${ }^{\circ}$ they do not protect against sexually transmitted diseases. In the 1980 s the HIV epidemic brought a new element into the discus- 
sion on contraceptive methods. " Teenagers seemed to be at high risk because casual sexual contacts are common. ${ }^{9}$ An increased transmission of HIV and other sexually transmitted diseases could be an unintentional consequence of the widespread use of the pill. On the other hand, increasing knowledge about AIDS could be expected to reduce the prescription of oral contraceptives for young girls. Oral contraceptives also have other health consequences. They carry an increased risk of cardiovascular diseases, ${ }^{36}$ although since the newer oral contraceptives contain less oestrogen and progestogen the risk may be lower than in the past." The use of oral contraceptives also seems to be related to an increased risk of certain neoplastic diseases, but a reduction in other forms of cancer. ${ }^{50}$ Widespread use of oral contraceptives may increase the number of negative health consequences in the female population; in young women certain cardiovascular diseases are relevant.

We report here national trends in the use of oral contraceptives among Finnish adolescents from 1981 to 1991. National trends in pregnancy, fertility, and abortion rates are examined to see whether the changes parallel those in the use of oral contraceptives.

\section{Subjects and methods}

The adolescent health and lifestyle survey was started in Finland in 1977." A questionnaire was posted to a representative sample of 14,16 and 18 year old boys and girls in February every other year. The comparability of the results from each survey was guaranteed by keeping the method of data collection, timing of the study, and sample obtained from the Population Register Centre similar. The samples were based on a particular date of birth so that all Finns born on the sample days were included $(6,12$, or 18 consecutive dates in July, in some years also June and August). The age variation was the smallest possible in each age group. Table I shows the number of respondents and the response rates.

Respondents were asked about their present use of oral contraceptives from the 1981 survey onwards. They were also asked whether they were married, unmarried, cohabiting, or going steady. Those who reported that they were going steady, cohabitating, or married were defined as having a steady partner. Most of those defined as having a steady partner were going steady since the proportion of girls who were married or cohabitating was only $8 \%$ among 18 year olds, $1 \%$ among the 16 year olds, and $0 \%$ among the 14 year olds. The length of the relationship with a steady partner was not asked. Adolescents use slightly different definitions for the concept going steady at different ages. Those aged 14 may say that they are going steady even after a few days' relationship but for older teenagers going steady usually means a more intense relationship in which more time is spent alone with the partner and sexual intercourse is more common. ${ }^{12}$

The annual number of abortions was obtained from the abortion registry held by the National Agency of Social Welfare and Health, to which hospitals and doctors are obliged to notify each induced abortion. The number of births was obtained from population statistics (Central Statistical Office of Finland, unpublished data $)^{1314}$ and the incidence rates of sexually transmitted diseases were taken from the official statistics based on the compulsory notification of cases (National Agency of Social Welfare and Health, unpublished statistical data). ${ }^{1510}$ Until 1986 doctors were obliged to notify verified and suspected cases of syphilis and gonorrhoea. From 1987 onwards, the notification system was reorganised and chlamydial and HIV infection were added to the list.
The number of deaths from cardiovascular causes was obtained from national mortality statistics ${ }^{1 i}$ is and the number of hospital discharges after admission for cardiovascular disease from the national hospital discharge registry compiled by the National Agency of Social Welfare and Health. The change in classification from the eighth revision of the ICD to the ninth revision at the beginning of 1987 made comparisons difficult. This was especially true for the hospital discharge data, for which individual doctors fill out the ICD code. The least biased time trends were obtained for a combination of pulmonary embolism (ICD 8th 450, ICD 9th 415), cerebrovascular diseases (ICD 430-438), and venous thromboembolic diseases (ICD $451,453)$. In 1987-1989, a more specific diagnosis of deep vein thrombosis of the leg (ICD 4511A, 9th revision) was studied too.

The fertility rate was calculated by dividing the annual number of births in an age group by the mean female population in that age group. The abortion rate was calculated in a corresponding way. The pregnancy rate was the sum of the abortion and fertility rates. A test for a linear trend in proportions was used in untransformed data to test whether changes in the rate were significant. ${ }^{19}$ A departure from linearity was tested for each trend but it was not significant for any of them. Confidence intervals were calculated by Wilson's approximate method.

\section{Results}

The proportion of teenagers taking oral contraceptives increased significantly $(p<0.001)$ from 1981-91 among the 16 and 18 year olds (figure) as well as among 14 year olds (table II). In 1991, the proportion taking oral contraceptives was $41 \cdot 3 \%$ (95\% confidence interval $38.4 \%$ to $44 \cdot 3 \%)$ among the 18 year olds $(n=1053)$, $17 \cdot 9 \%(15 \cdot 8 \%$ to $20 \cdot 2 \%)$ among 16 year olds $(n=1297)$, and $2.5 \%(1.7 \%$ to $3.5 \%)$ among 14 year olds $(n=1255)$.
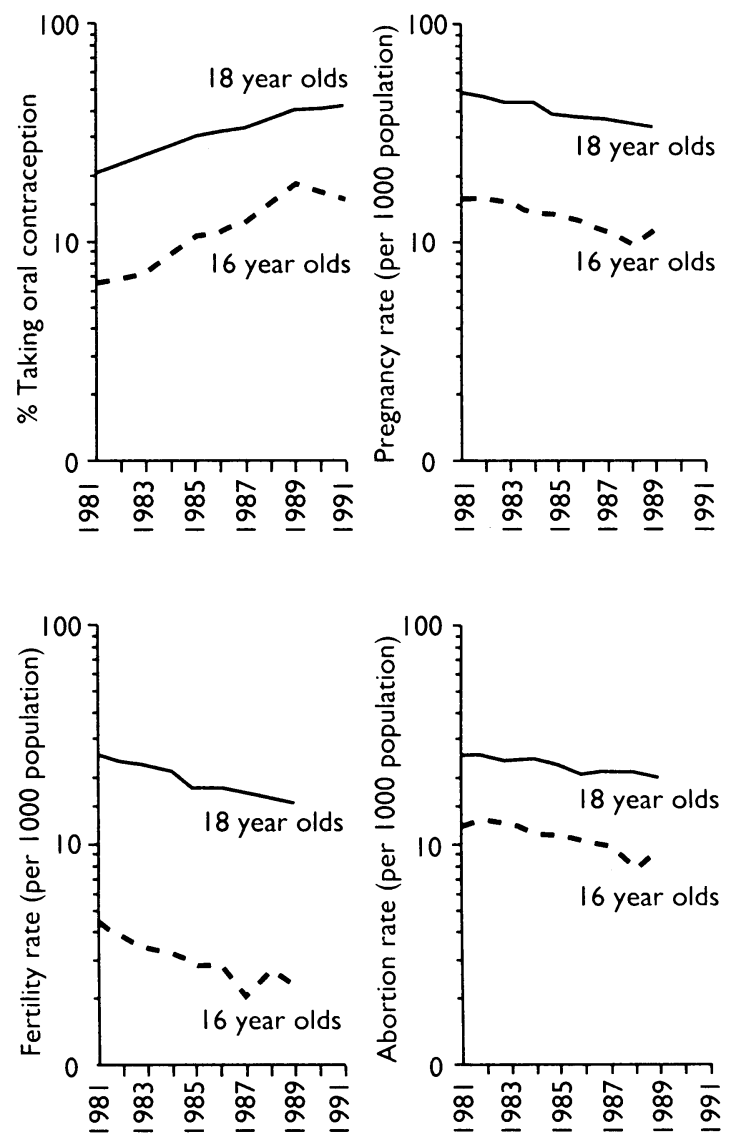

Percentage taking oral contraceptives and pregnancy, fertility, and abortion rates (per 1000) among 16 and 18 year olds, 1981-91 
TABLE II-Numbers (percentages) of 14 year old girls taking oral contraceptives and pregnancy, fertility, and abortion rates (per 1000 girls) 1981-91

\begin{tabular}{|c|c|c|c|c|c|c|c|}
\hline Rate & $1981-2$ & $1983-4$ & $1985-6$ & $1987-8$ & 1989 & 1991 & $\begin{array}{l}p \text { Value for } \\
\text { linear trend }\end{array}$ \\
\hline No (\%) taking oral contraceptives & $1(0 \cdot 2)$ & $2(0 \cdot 5)$ & $2(0 \cdot 5)$ & $14(1 \cdot 2)$ & $6(1 \cdot 4)$ & $31(2 \cdot 5)$ & $<0.001$ \\
\hline Pregnancy rate & 1.09 & 0.97 & 0.85 & 1.07 & $0 \cdot 80$ & & NS \\
\hline Fertility rate & $0 \cdot 18$ & $0 \cdot 10$ & $0 \cdot 11$ & 0.08 & 0.03 & & $<0.05$ \\
\hline Abortion rate & 0.91 & 0.86 & 0.77 & 0.98 & 0.77 & & NS \\
\hline
\end{tabular}

TABLE III-Incidence of gonorrhoea acuta ${ }^{*}$ (per 100000) and rate of hospital discharges (per 100000) after admission for venous thromboembolic disease among females aged 15 to 19 years, $1979-90$

p Value for

Disease 197919801981198219831984198519861987198819891990 lineartrend

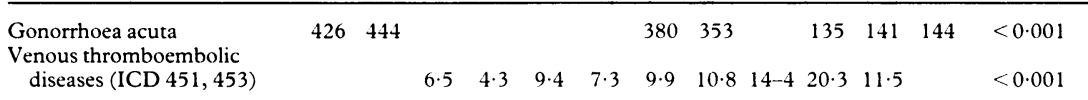

* Suspected and verified cases in 1979 to 1986 , only laboratory verified cases in 1988 to 1990.

The proportion of teenagers who had a steady partner did not significantly change from 1981 to 1991 . This proportion was $51 \%$ of the 18 year olds in 1981 and since then $55-57 \%$. Among the 14 year olds the proportion varied between $12 \%$ and $15 \%$ and among the 16 year olds between $34 \%$ and $38 \%$. Most teenagers taking oral contraceptives had a steady partner in each survey. In 1991 , this proportion was $80 \%(n=172)$ of the 16 year olds and $85 \%(n=366)$ of the 18 year olds.

Pregnancy rates decreased significantly in the 1980 s $(p<0.001)$ among 16 and 18 year olds (figure). The decrease was attributable to a decrease in the fertility and abortion rates both of which showed significant downward trends $(p<0.001)$. In 1989 the pregnancy rate was 11.6 per 100016 year olds and 34.5 per 1000 in 18 year olds. The abortion rates were 9.3 and 19.2 and the fertility rates were 2.7 and $15 \cdot 3$, correspondingly. The rates for 14 year olds were studied by two year averages because of small numbers. The fertility rate decreased significantly but changes in the pregnancy and abortion rates were small (table II).

The incidence of gonorrhoea decreased among females aged 15 to 19 years in the 1980 s (table III). The steep decrease between 1986 and 1988 may be partly explained by the fact that from 1988 onwards only the rate of the laboratory verified cases of gonorrhoea was published. Syphilis was very rare in this age group, with only a few cases a year. Only seven cases of HIV infection were observed in the years 1980 to 1990 in the 15-19 years age group. In the $20-24$ age group 55 cases were recorded. Most of the cases were in men.

From 1981 to 1989 deaths from pulmonary embolism, cerebrovascular diseases, and venous thromboembolic diseases in females aged 15 to 19 were only sporadic: none, one, or two cases per year altogether. No systematic trend was observed. The rates of hospital discharges with pulmonary embolism varied between 0.3 and 3 per 100000 girls and that of cerebrovascular diseases between 7 and 16 but there was no systematic trend. An increasing trend was observed in venous thromboembolic diseases (table III). The rate of hospital discharges after deep vein thrombosis was available only since 1987 and showed no increase between 1987 and 1989.

\section{Discussion}

We have presented trends in use of oral contraceptives based on highly comparable national surveys. The age variation in each age group was the smallest possible and similar methods in the data collection in each survey guaranteed comparability as far as possible.

The proportion of Finnish teenagers taking oral contraceptives nearly tripled from 1981 to 1991 . In 1991 , nearly half of the 18 year olds and one fifth of the
16 year olds took oral contraceptives. Simultaneously, the fertility and abortion rates went down. Two factors can explain the decreasing trends in fertility and abortion rates: decrease in the rate of sexual intercourse or more effective contraception. There is no evidence that sexual intercourse among teenagers in Finland fell. Indeed, small scale surveys report an increased rate from the 1960 s to the late 1980 s. $^{\circ}$ Our data also showed that the proportion of the girls who had a steady partner did not change in the 1980 s. Data on the changes in condom use in the 1980s are not available for teenagers. The sale of condoms had decreased but this is because of a change in the population structure (Finnish Population and Family Welfare Federation, personal communication). Use of intrauterine devices has decreased in Finland in the $1980 \mathrm{~s}^{21121}$ and they are not recommended for teenagers.

The most likely explanation for decreasing abortion and fertility rates seems to be more effective contraception arising from increased use of oral contraceptives. Oral contraceptives are mostly taken by the young women who have the highest sexual exposure.22 Earlier Finnish studies have shown that nearly all the teenaged girls who had an abortion had been in a steady relationship with their partner for at least two months. ${ }^{23}$ Swedish data support the conclusion that an increase in use of oral contraceptives effectively decreases abortions and childbirths: a decrease in use of oral contraceptives in the middle of the 1980s was followed by an increase in abortion and fertility rates-especially among teenaged girls. ${ }^{24}$

Only a slight decrease in pregnancies was found among 14 year old girls, which was attributable to decreasing childbirths but not abortions. But the proportion of girls taking the oral contraceptive in this age group was still low at the end of the study; only $2.5 \%$. The abortion and fertility rates as well as the absolute numbers were also low (20-40 abortions and only a few births per year). If the proportion of 14 year olds taking oral contraceptives increased, a decreasing trend in the abortion rates might be achieved in this age group too.

\section{SEXUAILY TRANSMITTED DISEASE}

Our data did not confirm the hypothesis that increased use of oral contraceptives would increase the incidence of sexually transmitted diseases. The rate of HIV infection remained low among adolescents as well as among adults ${ }^{25}$ and the incidence of gonorrhoea fell while that of syphilis was stable and very low. Unfortunately, information on the spread of chlamydia, papilloma virus, and genital herpes simplex virus was not available, except that from 1988 to 1990 rates of chlamydia infection did not change. Although adolescents often have casual sexual contacts, ${ }^{9}$ oral contraceptives are mostly taken by those adolescents who have a steady partner. Thus, this group may not be at a high risk of contracting HIV or other sexually transmitted diseases.

The threat of the HIV infection might decrease the use of oral contraceptives by young women. There is evidence that this has taken place in the United States $^{26}$ and in Sweden, where increasing pregnancy rates among adolescents were observed. ${ }^{24}$ In Finland, at least, it seems that increased use of oral contraceptives among adolescents affects the pregnancy rates but not necessarily the rates of sexually transmitted diseases. Finland, is a Western welfare state with a liberal attitude towards sex and effective family planning services and this conclusion may not be valid in other societies with different sexual patterns and a high prevalence of HIV infection.

OTHER DISEASE

The only alarming finding was that the hospital 
discharges after venous thromboembolic diseases among teenaged girls increased slightly in the 1980s. Nevertheless, no change was observed in rates of pulmonary embolism or cerebrovascular diseases and the mortality from none of these increased. A casecontrol study in England and Wales found no significant excess of oral contraceptive use among young women dying of venous thromboembolism. ${ }^{27}$ Although the health risks of the present oral contraceptives are low, especially in young women, ${ }^{5611}$ it remains possible that they could increase the risk of venous thromboembolic diseases. The effect is unlikely to be seen in the death rates in a country with a comprehensive and well functioning health care system. However, because of changes in the registration of hospital discharges in 1987 and the somewhat unreliable nature of the original data, our results are not definitive and further epidemiological studies are needed before drawing conclusions.

The question of long term health consequences is essential and difficult to answer. Firstly, we have new generations of girls who have started taking oral contraceptives at an early age and whose total length of oral contraceptive use may be much longer than that of previous cohorts. Secondly, they are mainly taking low doses or microdoses of oestrogen, and new progestogen components have also been introduced. Earlier long term follow up studies are therefore not directly applicable in this situation. Although the cardiovascular risk seems to diminish," "1" some questions remain unanswered: the published data about cervical neoplasia and long term use of oral contraceptives are somewhat confusing and need further investigations. ${ }^{2 \times-30}$

\section{INCREASED USE OF ORAL CONTRACEPTIVES}

Which factor contributed to a rapid and continuing increase in the use of oral contraceptives when there was no evidence that the need for contraceptives has increased? The three major factors are prescribing patterns of doctors, access to family planning services, and sex education and public opinion.

Oral contraceptives are available only with a doctor's prescription; access to family planning services and attitudes of doctors effectively regulate their use. The first new low oestrogen products were registered in Finland in $1974^{31}$ and in 1979 the low oestrogen combination pills were recommended for teenaged girls in Finnish medical publications, although with certain reservations. In the early 1980s many articles published by the Finnish medical journals, advocated low dose and microdose oestrogen pills as a safe contraceptive method for teenaged girls.

In 1972 Finland set up a free family planning service run by the local municipalities throughout the country. ${ }^{32}$ The first contraceptive method is supplied free of charge (for example, pills for nine months). Starting from the 1970s, young girls may have benefited from these services or visited a school nurse or doctor without their parents' knowledge.

In the late 'seventies, strong emphasis was put on sex education both at the national level and in the schools. A national plan for sex education was published by the working group set up by the Ministry of Health, and more detailed guidelines were given by the national health and education authorities. The main concern has been put on ensuring practise of safer sex, which typically refers to practices for avoiding pregnancy and sexually transmitted diseases. There were no active antisexual or antiabortion movements in Finland in the 1980 s, which might have prevented the functioning of family planning services or altered the prescription practices of physicians.

The network of family planning services may have contributed to the fact that information on the possible increased risk of breast cancer after taking oral contraceptives $^{33}$ did not seem to decrease the use among adolescents, even though one fifth of 17 year olds were afraid of side effects of the pills in the latter half of the 1980s. ${ }^{22}$ In Finland, public discussion about risk of breast cancer was moderate and the media reports did not exaggerate the problem. ${ }^{34}$ Campaigns to increase awareness of the risks of HIV infection and promote use of condoms in the late $1980 \mathrm{~s}^{35}$ did not affect the trend in use of oral contraceptives either. Such campaigns have affected use of oral contraceptives in Sweden and the United States. ${ }^{24} 26$

We believe that a well organised system of family planning services for teenagers supported by active sex education has had a considerable impact on the prevalence of oral contraceptive use-and through that-on abortion and fertility rates among adolescent girls. International comparisons have also shown that the use of oral contraceptives among teenagers is higher in countries where family planning services for teenagers are confidential, free, and accessible, and that teenage pregnancy rates are lower in countries where there is greater availability of contraceptive services. ${ }^{236}$ Because of the threat of the HIV infection, the use of the condom has been emphasised tremendously in recent years. However, the threat of AIDS should not be allowed to decrease the use of oral contraceptives among adolescents since this may have unintentional effects on teenage pregnancy rates.

This study was supported by the National Agency for Social Welfare and Health of Finland and the Yriö Jahnsson Foundation. We thank Ms Anja Rasimus from the National Agency for Social Welfare and Health for providing unpublished statistical data.

1 Brooks-Gunn J, Paikoff R. Promoting healthy behavior in adolescence: the case of sexuality and pregnancy. Bull NY Acad Med 1991;76:527-47.

2 United Nations Department of International Economic and Social Affair Adolescent reproductive behaviour. Evidence from developed countries. Population Studies 1988:109/1:1-177.

3 Tyrer LB, Josimovich J. Contraception in teenagers. Clin Obslet Gynecol 1977;20:651-63

4 Turetsky RA, Strasburger VC. Adolescent contraception. Review and recommendations. Clin Pediatr 1983;22:337-41.

5 Hofmann A. Contraception in adolescence: a review. 2. Biomedical aspects. Bull World Health Organ 1984:62:331-44.

6 DaVanzo J, Parnell AM, Foege WH. Health consequences of contraceptive use and reproductive patterns. Summary of a report from the US National use and reproductive patterns. Summary of a

7 Harris C, Small CB, Klein RE, Friedland GH, Small CB, Emeson EE, et al. Immunodeficiency in female sexual partners of men with the acquired immunodeficiency syndrome. N Engl f Med 1983;308:1181

Redfield R, Markham P, Salahuddin S, Wright C, Sarngadharan M, Gallo R. Heterosexually acquired HTLV-III/LAV disease (AIDS-related complex and AIDS). Epidemiologic evidence for female-to-male transmission. FAMA 1985;254:2094-6

9 Kontula O, Rimpelä M, Ojanlatva A. Sexual knowledge, attitudes, fears and behaviors of adolescents in Finland (the KISS study). Health Education Research 1992;7:69-77.

10 Thorogood $M$, Vessey $M$. An epidemiologic survey of cardiovascular disease in women taking oral contraceptives. Am f Obstet Gynecol 1990;163(Pt 2): women $274-81$.

11 Rimpelä M, Rimpelä A, Rahkonen $O$, Teperi J. The evolution of the juvenile health habit study 1977-85. In: Anderson R, Davies JK, Kickbush I, McQueen DV, eds. Health behaviour research and health promotion. Oxford: Oxford University Press, 1988

12 Kontula O. Sukupuolielämän aloittamisen yhteiskunnallisista ehdoista. Helsinki: VAPK-kustannus, 1991

13 Central Statistical Office of Finland. Structure of population and vital statistics 1980-6. Official Statistics of Finland IV A 1980-6:145-53.

4 Central Statistical Office of Finland. Structure of population and vital statistics 1987-8. Official Statistics of Finland, Population 1990-1:7.

15 National Board of Health in Finland. Health Services 1981. Official Statistics of Finland XI:77.

16 National Board of Health in Finland. Health services 1987. Official Statistics of Finland 1989;3:22

17 Central Statistical Office of Finland. Causes of death in Finland 1980-6. Official Statistics of Finland VI B 1980-6;136-142.

18 Central Statistical Office of Finland. Causes of death in Finland 1987-9. Official Statistics of Finland, Health, 1987-89;4-6.

19 Armitage P. Statistical methods in medical research. Oxford: Blackwell Scientific, 1971

20 Makkonen K, Hemminki E. Different contraceptive practices: Use of contraceptives in Finland and other Nordic countries in the 1970s and 1980s. Siand $\tilde{J}$ Soc Med 1991;19:32-8.

21 Nordic Medico-Statistical Committee. Health Statistics in the Nordic Countries 1966-1991. Copenhagen: NOMESCO 1991:36.

22 Kontula $\mathrm{O}$, Meriläinen J. Adolescent maturation to courtship and sexuality. Helsinki: National Board of Health, 1988. (Health education series original reports 9/1988.) (In Finnish, English summary). 
23 Ruusuvaara L. Teenage abortions, family backgrotend, scxual experience and contraceptive use. [dissertation]. Helsinki: Lniversity of Helsinki, 1983.

24 Holmgren K. Stigande aborttal i Sverige. Dags för sexologispecialitet? Nord Med 1990;105:46-8

25 Sosiaali- ja tervevshallitus. Tilastojulkaisu 1991. Tartuntatautitilann ruosina 1988-1990 ja rokotukset zuosina 1987-1990 Suomessa. Helsinki: Oy Ylipistopaino, 1991.

26 DeBuono B, Zinner S, Daamen M, McCormack W. Sexual behavior of college women in 1975, 1986, and 1989. N Engl f.Med 1990:322:821-5.

7 Thorogod $\mathrm{M}$ Mann J Murphy $\mathrm{I}$ Vessey $\mathrm{M}$ Risk factors for fatal venous hroge

thromboembism in

feriew. $\mathrm{Br}$ Obstet Grnaecol 1987;94:724-30

Beral V, Hannaford P. Clifford K. Oral contraceptive use and malignancies of the genital tract. Lancet 1988 ;ii:1331-5.

30 Brinton LA. Oral contraceptives and cervical ncoplasia. Contraception 1991; 43:581-95.
31 Hirvonen E, Idänpää-Heikkilä J. Cardiovascular death among women under 40 years of age using low-estrogen oral contraceptives and intrauterine devices in Finland from 1975 to 1984. Am f Obstet Gynecol 1990;163:281-4.

32 Wallace H, Vienonen M. Teenage pregnancy in Sweden and Finland Implications for the United States. F Adolesc Health Care 1989:10:231-6.

33 Pike MC, Henderson BE, Krailo MD, Duke A, Roy S. Breast cancer in young women and use of oral contraceptives: possible modifying effects of formulation and age at use Lancet 1983;ii:926-30.

34 Mandelin M. Stabilt antal aborter i Finland. Nord Med 1990;105:41

35 Tikkanen J, Koskela K, Haikala O. Finnish response to human immunodeficiency virus infection. Hugic 1988:77:28-31.

36 Jones EF, Forrest JD, Goldman N, Hensaw SK, Lincoln R, Rosoff JI, et al. Teenage pregnancy in developed countries: determinants and policy implications. Fam Plann Perspect 1985;17:53-63.

Accopted 3 September 1992)
Department of Medicine,

Muhimbili Medical Centre,

University of Dar es

Salaam, Dar es Salaam,

Tanzania

Andrew B Swai, senior

lecturer in medicine

Donald G McLarty, professor

of medicine

Ministry of Health, Dar es

Salaam, Tanzania

Henry M Kitange, specialist physician

Gabriel Masuki, district

medical officer

Peter M Kilima, community physician

Human Diabetes and Metabolism Research Centre, University of Newcastle upon Tyne, Newcastle upon Tyne NE2 4HH

K George M M Alberti, professor of medicine

Correspondence to: Professor Alberti.

BM7 1992;305:1057-62

\title{
Is diabetes mellitus related to undernutrition in rural Tanzania?//
}

\author{
Andrew B⿺Swai, Henry M_Kitange, Gabriel Masuki, Peter ML Kilima, K George M M Alberti, \\ Donald GMcLarty
}

Abstract

Objective-To investigate the relation between undernutrition and diabetes.

Design-Survey of glucose tolerance in rural Tanzania.

Setting-Eight villages in three widely separated regions of Tanzania.

Subjects-8581 people aged 15 and above: 3705 men and 4876 women.

Main outcome measures-Oral glucose tolerance, body mass index, height, and low haemoglobin and cholesterol concentrations.

Results-In the eight villages $42 \cdot 7-56 \cdot 9 \%$ of all men and $30 \cdot 0-45 \cdot 2 \%$ of all women had a body mass index below $20 \mathrm{~kg} / \mathrm{m}^{2}$; the lowest quintile was $18.2 \mathrm{~kg} / \mathrm{m}^{2}$ in men and $18.6 \mathrm{~kg} / \mathrm{m}^{2}$ in women. The prevalence of diabetes did not change significantly from the lowest to the highest fifths of body mass index in men (lowest $1.6 \%$ (95\% confidence interval $0.8 \%$ to $2 \cdot 9 \%$ ) $v$ highest $1 \cdot 3 \%(0.7 \%$ to $2 \cdot 5 \%)$ ) or women $(1 \cdot 1 \%(0 \cdot 6 \%$ to $2 \cdot 1 \%) v 0 \cdot 5 \%(0 \cdot 2 \%$ to $1 \cdot 2 \%))$. In men and in women prevalence of impaired glucose tolerance was greater in the lowest fifths of height $(8 \cdot 2 \%(6 \cdot 3 \%$ to $10 \cdot 6 \%)$, and $11 \cdot 1 \%(9 \cdot 2 \%$ to $13 \cdot 3 \%)$ ) respectively and body mass index $(9 \cdot 6 \%$ $(7 \cdot 5 \%$ to $12 \cdot 1 \%)$, and $8 \cdot 4 \%(6 \cdot 7 \%$ to $10 \cdot 5 \%)$ than in the highest fifths (impaired glucose tolerance $\mathbf{4} \cdot \mathbf{7 \%}$ $(3 \cdot 4 \%$ to $6 \cdot 5 \%)$; and $5 \cdot 1 \%(3.9 \%$ to $6 \cdot 7 \%)$; body mass index $5 \cdot 1 \%(3 \cdot 7 \%$ to $7 \cdot 0 \%)$, and $7 \cdot 7 \%(6 \cdot 2 \%$ to $9 \cdot 6 \%)$.

Conclusion-Rates of diabetes were not significantly associated with low body mass index or height, but overall rates were much lower than those in well nourished Western populations. Increased impaired glucose tolerance in the most malnourished people may reflect the larger glucose load per kilogram weight. The role of undernutrition in the aetiology of diabetes must be questioned.

\section{Introduction}

In 1985 the World Health Organisation expert committee on diabetes mellitus introduced malnutrition related diabetes mellitus as "a major clinical subclass, ranking with insulin dependent diabetes mellitus and non-insulin dependent diabetes mellitus." Bajaj suggested that there are at least two subclasses of malnutrition related diabetes mellitus: fibrocalculous pancreatic diabetes and protein deficient pancreatic diabetes, and this classification has been adopted by the WHO.' Several reviews of malnutrition related diabetes have been published. ${ }^{3-7}$ Most have favoured the view that chronic undernutrition is a key factor in the causation of malnutrition related diabetes mellitus, but direct evidence is poor and we have questioned the existence of the protein deficient form of malnutrition related diabetes mellitus.

Traditionally a low body weight and energy intake were considered to decrease the risk of diabetes. ${ }^{\circ}$ This view was based on observations such as the reduced incidence of diabetes mellitus in Europe during the first and second world wars ${ }^{4}$ and the observation that the prevalence of non-insulin dependent diabetes in different countries was positively related to the "average fatness" of the population." The same association has been observed in intrapopulation studies. Gupta et al found that, among urban Indians, rates of diabetes were $3.6 \%$ in subjects with a normal body weight and $1.5 \%$ in very lean subjects." On the other hand, Rao cited the results of a large study in India in which rates of diabetes were not significantly different between urban and rural subjects as evidence pointing to an association between diabetes and undernutrition, since most rural subjects were undernourished. ${ }^{+}$In general, diabetes is less common in undernourished populations than in well nourished populations. ${ }^{12}$ This does not, however, answer the question clearly whether within the same population chronic undernutrition leads to a clinically and statistically significant increase in diabetes. We attempted to answer this question by studying glucose tolerance in rural African communities with a background of malnutrition.

\section{Patients and methods}

The study was carried out in eight villages in Tanzania and forms part of a long term programme aimed at reducing morbidity and mortality with continuing care. (Treatment was offered to all those found to be ill during surveys.) Six villages were chosen at random in two contrasting regions: Kilimanjaro, one of the most prosperous, and Morogoro region, one of the more economically disadvantaged..$^{13}$ Of the remaining two villages, one in Mara region was chosen because the inhabitants had been exposed to high concentrations of dietary cyanide, and the other in Kilimanjaro region was chosen because hypertension was thought to be common. In four of the eight villages the total population aged 15 years and over was about 1000 . The entire adult population in these villages was therefore invited to participate in the study. In the other villages a list of the names of the leaders of the 10 cell units (10 families) was obtained and the number of units required to provide about 1000 subjects was selected at random. Slightly more people were selected in Uswaa village. Lengthy discussions were held with village leaders before the start of the study to ensure 